\title{
Unveiling the shade nature of cyanic leaves: a view from the "blue absorbing side" of anthocyanins
}

\author{
Marco Landi ${ }^{1}$, Giovanni Agati ${ }^{2}$, Alessio Fini ${ }^{3}$, Lucia Guidi ${ }^{1}$, Federico Sebastiani ${ }^{4}$, Massimiliano Tattini ${ }^{4 *}$ \\ ${ }^{1}$ Department of Agriculture, Food and Environment, University of Pisa, Via del Borghetto 80, I-56124, Pisa, Italy \\ ${ }^{2}$ Institute of Applied Physics ‘Nello Carrara’, National Research Council of Italy, Via Madonna del Piano 10, I- \\ 50019, Sesto Fiorentino, Florence, Italy \\ ${ }^{3}$ Department of Agricultural and Environmental Sciences - Production, Landscape, Agroenergy University of \\ Milan, Via Celoria 2, I-20133, Milan, Italy \\ ${ }^{4}$ Institute for Sustainable Plant Protection, National Research Council of Italy, Via Madonna del Piano 10, I-50019, \\ Sesto Fiorentino, Florence, Italy
}

\section{RUNNING HEAD: ANTHOCYANINS ABSORB BLUE LIGHT EFFECTIVELY}

Author for correspondence

Massimiliano Tattini

Phone +39055 4574022

Email: massimiliano.tattini@ipsp.cnr.it

This article has been accepted for publication and undergone full peer review but has not been through the copyediting, typesetting, pagination and proofreading process which may lead to differences between this version and the Version of Record. Please cite this article as doi: 10.1111/pce.13818 


\section{Abstract}

Anthocyanins have long been suggested as having great potential in offering photoprotection to plants facing high light irradiance. Nonetheless, their effective ability in protecting the photosynthetic apparatus from supernumerary photons has been questioned by some authors, based upon the inexact belief that anthocyanins almost exclusively absorb green photons, which are poorly absorbed by chlorophylls. Here we focus on the blue light absorbing features of anthocyanins, a neglected issue in anthocyanin research. Anthocyanins effectively absorb blue photons: the absorbance of blue relative to green photons increases from tri- to mono-hydroxy B-ring substituted structures, reaching up to $50 \%$ of green photons absorption. We offer a comprehensive picture of the molecular events activated by low blue-light availability, extending our previous analysis in purple and green basil, which we suggest to be responsible for the "shade syndrome" displayed by cyanic leaves. While purple leaves display overexpression of genes promoting chlorophyll biosynthesis and light harvesting, in green leaves it is the genes involved in the stability/repair of photosystems that are largely overexpressed. As a corollary, this adds further support to the view of an effective photoprotective role of anthocyanins. We discuss the profound morphoanatomical adjustments imposed by the epidermal anthocyanin shield, which reflect adjustments in light harvesting capacity under imposed shade and make complex the analysis of the photosynthetic performance of cyanic vs acyanic leaves.

KEY WORDS: blue light, cyanic vs acyanic leaves, epidermal anthocyanins, photoprotection, photosynthesis, red light, shade avoidance responses, transcriptomics.

\section{INTRODUCTION}


Whether epidermal anthocyanins offer effective protection to plants facing excessive light is still a debated issue (for review articles, see Hughes, 2011; Manetas, 2006; Landi, Tattini, \& Gould, 2015; Steyn, Wand, Holcroft, \& Jacobs, 2002). There are several reasons responsible for this continued discussion. Although anthocyanins effectively absorb photons over a wide portion of the photosynthetic spectrum, many experiments comparing light stress responses of red versus green leaves lack true controls, and therefore many gaps in our understanding of photoprotection remain (Gould, Jay-Allemand, Logan, Baissac, \& Bidel, 2018; Tattini et al., 2017). First, juvenile red leaves or leaves that become transiently red during the winter season (so-called "winter reddening”) have been compared to co-occurring mature green (often shaded) leaves in many instances (Hughes, Neufeld, \& Burkey, 2005; Kytridis, Karageorgou, Levizou, \& Manetas, 2008; Ranjan, Singh, Singh, Pathre, \& Shirke, 2014; Zeliou, Manetas, \& Petropoulou, 2009; Zhang et al., 2018). This is problematic because many traits other than the biosynthesis of anthocyanins may largely vary between cyanic and acyanic leaves because of leaf age, season, and the light environment (Rasulov, Bichele, Laisk, \& Niinemets, 2014; Tattini et al., 2014). Second, the light irradiance at which plants have been grown differs strikingly among studies. In some instances, plants acclimated to relatively low irradiance (greenhouse/growth chamber studies) have been suddenly and transiently exposed to excessive light (Gould et al., 2018; Landi, Guidi, Pardossi, Tattini, \& Gould, 2014; Logan, Stafstrom, Walsh, Reblin, \& Gould, 2015). Other studies have instead compared cyanic and acyanic individuals exposed for long periods to high light irradiance in the field (Liakopoulos et al., 2006; Tattini et al., 2017; Zhang, Zhong, Wang, Sui, \& Xu, 2016). Third, there is the general, inexact belief that anthocyanins are effective in absorbing photons over the green region (over the 500-550 nm waveband), but quite ineffective in absorbing photons over other portions of the visible solar spectrum (Hughes, 2011; Kyparissis, Grammatikopoulos, \& Manetas, 2007; Steyn et al., 2002). It has been argued, therefore, that anthocyanins may play only a marginal role in photoprotection (Liakopoulos et al., 2006; Neill \& Gould, 1999; Nikoforou, Nikopoulos, \& Manetas, 2011), given the fact that 
chlorophylls mostly absorb over the blue $(400-500 \mathrm{~nm})$ and the red $(600-700 \mathrm{~nm})$, but relatively little over the green portion of the solar spectrum. Nonetheless, light-induced depression in both maximal $\left(\mathrm{F}_{\mathrm{v}} / \mathrm{F}_{\mathrm{m}}\right)$ and operational ( $\left.\Phi_{\text {PSII }}\right)$ photosystem II (PSII) quantum yield is lower in cyanic compared to acyanic leaves over a broad range of species (Gould et al., 2018; Hughes \& Smith, 2007; Landi et al., 2014; Tattini et al., 2017). There is also evidence that photoinhibition (Long, Humphries, \& Falkowski, 1994), estimated from morning-to-midday depression in photosynthesis, is lower in "constitutively" cyanic leaves (leaves that remain red throughout their entire life cycle) as compared to their green counterparts (Tattini et al., 2014; 2017). Therefore, it is conceivable the photoprotective functions of anthocyanins mostly depend upon their effective ability to absorb blue photons (and red photons to a lesser degree, Fig. 1A), though they have molar extinction coefficient (E) maxima in the 510-540 nm waveband (Jordheim et al., 2016; Merzlyak, Chivkunova, Solovchenko, \& Naqvi, 2008; Tattini et al., 2014; Gould et al., 2018).

Cyanic leaves (and individuals) display the so-called ”shade syndrome” (Manetas, Petropoulou, Psara, \& Drinia, 2003; Tattini et al., 2014), a suite of correlated traits aimed at both avoiding and acclimating to low light availability. Notably, the shade avoidance responses in leaves and individuals are induced by high green light availability (Dhingra, Dies, Lehner, \& Folta, 2006; Wang \& Folta, 2013; Smith, McAuslan, \& Murchie, 2017), as is the case of leaves growing in the understory (true shade leaves), which perceive light strongly enriched in green f far-red (FR) wavelengths. Indeed, green light stimulates early stem elongation, and opposes responses to blueand red light-activated signaling pathways (e.g. blue/red light-induced stomatal opening, Folta \& Mahrunic, 2007). Similarly, transcripts of genes encoding for light-induced proteins associated to PSI, PSII and the stroma (such as psaA, psbD, and rbcL, Christopher and Mullet, 1994; Folta \& Kaufmann, 2003; Nakamura et al., 2003) are largely downregulated upon a pulse of green light (Dhingra et al., 2006; Wang \& Folta, 2013). We conclude, therefore, that the "shade syndrome/nature" of cyanic leaves does not fit with the "green absorbing” features of anthocyanins. 
We also argue that the shade nature of cyanic leaves is unlikely to be the result of the UV-screening ability of anthocyanins, which may be considerable for anthocyanins acylated with hydroxycinnamic acid derivatives (Jordheim et al., 2016; Tattini et al., 2014; Fig. S1 in Supporting Information). Effective UV-absorbing compounds, such as the colorless flavonols, accumulate more in high-light exposed green leaves compared to their corresponding red counterparts (Tattini et al., 2014; 2017), consistent with the strong competition between flavonol and anthocyanin biosynthetic pathways (Yuan, Rebocho, Sagawa, Stanley, \& Bradshaw, 2016). The lower UVabsorbing potential of red compared to green leaves should indeed oppose the shade avoidance response (Hayes, Velanis, Jenkins, \& Franklin, 2014; Mazza \& Ballarè, 2015).

On the other hand, the ability of anthocyanins in absorbing over the red waveband, thus reducing the red (R) to far-red (FR) ratio (R/FR), as occurs when leaves grow under a dense canopy (Franklin, 2008), may be responsible for the shade syndrome displayed by cyanic leaves. The absorption spectra of anthocyanins, especially when conjugated with “colorless” flavonoids (so-called co-pigmentation, Trouilas et al., 2016) may have an appreciable tail over the 600-630 nm waveband (Gould et al., 2018; Jordheim et al., 2016; Fig. 1A). Since the epidermal concentration of colorless flavonoids is high enough (low mM range, Agati \& Tattini, 2010) even in red leaves growing in natural sunlight (Tattini et al., 2014, 2017), co-pigmentation is strongly favored (Mazza \& Brouillard, 1990). The extent to which the "red-absorbing" properties of anthocyanins contribute to the shade jidance responses in cyanic leaves represents a still unexplored issue of great significance, given that anthocyanins may alter to some extent the R/FR in some species (Fig. 1B). The ability of anthocyanins to absorb red wavelengths, and hence their ability to modulate the photochemical activity of phytochromes, increases with their concentration, the degree of B-ring hydroxylation and the nature of acyl substituents (Merzlyak et al., 2008, Figs. 1B, Fig. S1 in Supporting Information). This matter deserves deeper investigation, since true shade leaves 
may experience R/FR ratios even an order of magnitude lower than those perceived by leaves growing in full sunlight (Fankhauser \& Batschauer, 2016).

The functional significance of blue-light absorption by epidermal anthocyanins was emphasized early on (Chalker-Scott, 1999; Drumm-Herrell \& Mohr, 1985, Feild, Lee \& Holbrook, 2001), but largely ignored thereafter. However, anthocyanins have an effective ability to absorb photons over the blue portion of the solar spectrum (Fig. 1). This capacity depends on both the number of hydroxyl groups on the B-ring of the flavonoid skeleton (with the monohydroxy B-ring substituted structures, e.g. pelargonidin, having the highest blue to green absorbance ratio, Rein, Ollilainen, Vahermo, Yli-Kauhaluoma \& Heinonen, 2005; Halbwirth, 2010) and substituents bound to the glycosyl moieties (i.e. different acylations, Fig. S1 in Supporting Information). For instance, red stems of Cornus stolonifera transmitted just 25\% of blue light as compared to green stems (Cooney, Schafer, Logan, Cox, \& Gould, 2015; Gould, Dudle, \& Neufeld, 2010). Blue light absorption by the epidermal peel of activation-tagged pap1-D (production of anthocyanin pigment 1- Dominant) mutant of Arabidopsis was as much as $70 \%$ of the absorbance over the green-yellow waveband (Gould et al., 2018). The blue absorbance (over the 450-500 nm blue-waveband) of epidermal anthocyanins (the pool consisting of the 3-O-glucosides of both pelargonidin and cyanidin, and p-coumaroyl derivatives of cyanidin 3-O-glucoside) extracted from purple basil leaves grown in full sunlight was as much as 73\% of the absorbance over the 500-550 nm green-waveband (Tattini l., 2014). Notably, the in vivo absorbance of vacuolar anthocyanins (measured using micro-spectrophotometry) over the blue waveband was on average $50 \%$ of that within the green waveband in a range of reddish species (Merzlyak et al., 2008).

The decline in blue photons reaching the photosynthetic apparatus limits the efficient use of incident radiant energy for photosynthesis and imposes on cyanic leaves a profound adjustment in the light harvesting system (Horton, 2012; Ruban, 2018). Consistently, cyanic leaves have much greater concentration of chlorophylls 
(Chl), a significantly lower Chla to Chlb ratio (Chla/Chlb) and usually display lower photosynthetic rates than the green counterparts (Gould, Vogelmann, Han, \& Clearwater, 2002; Menzies et al., 2015; Zhang et al., 2018), unless when exposed to high solar irradiance for an extended period of time (Liakopoulos et al., 2006;; Tattini et al., 2014; 2017) or in the case of abaxial anthocyanins (Hughes et al., 2014). These observations clearly explain the shade nature displayed by cyanic leaves, even when growing in full sunlight (Manetas et al., 2003; Hughes et al., 2005; Tattini et al., 2017; Zeliou et al., 2009). In fact, red leaves are thinner with less compact mesophyll tissues and a lower proportion of palisade to spongy parenchyma with respect to green leaves (Boardmann, 1977; Franklin, 2008; Manetas et al., 2003; Kyparissis et al., 2007; Tattini et al., 2014). The shade nature of cyanic leaves is also manifested through a lower concentration of de-epoxided xanthophylls, and consequently, by a lower potential (or by a lower need, Tattini et al., 2017) to dissipate excess energy via nonphotochemical quenching (NPQ) compared to green leaves, irrespective of light availability (Landi et al., 2015; Tattini et al., 2014).

Here we focus on the suite of molecular events, which operate at very different levels of scale (from cellular to organism, up to whole-plant levels), and that follow blue light absorption by epidermal anthocyanins. We offer clear evidence that the blue-light absorbing properties of anthocyanins largely contribute to the shade nature of cyanic leaves/individuals. As a corollary, this strongly supports the view of an effective photoprotective role of anthocyanins that is consistent with the notion that blue light contributes substantially to the action spectrum photodamage (Takahashi et al., 2010). We cannot exclude the fact that anthocyanins contribute to the shade syndrome by both decreasing the R/FR and potentially altering the cryptochrome/phytochrome-mediated signaling pathways. However, this issue lacks substantial experimental evidence and, hence, will only be briefly discussed in this article. 


\section{DISSECTING MOLECULAR EVENTS AT THE BASE OF THE SHADE NATURE OF}

\section{CYANIC LEAVES}

Low blue light availability evokes shade avoidance responses similar to those induced by low R/FR (Sellaro et al., 2010; Pedmale et al., 2016), and the cellular reprogramming caused by blue light depletion may be even larger than in response to a decrease in R/FR (Ballarè \& Pierik, 2017; Ballarè, Scopel, \& Sanchez, 1990). Plants are very sensitive to changes in blue light irradiance, as up to $26 \%$ of gene expression varies in response to blue light, even on a very short time-scale (Jiao et al., 2003). This conforms to the notions that low blue light is an indicator of actual shading, whereas plants use the reduction in R/FR as an early warning signal of future competition (Ballaré et al., 1990; Keuskamp, Keller, Ballarè, \& Pierik, 2012). As outlined above, anthocyanins are capable of strongly affecting cryptochrome- and, to a lesser extent, phytochrome-mediated signaling pathways (Fig. 1B). This conflicts with the hypothesis that the reason anthocyanins absorb green light is so that they can be accumulated in high concentrations without affecting signaling processes controlled by phytochrome and cryptochrome (McClure, 1975). The blue light absorbing properties of anthocyanins are therefore of extreme value when both exploring response mechanisms of green vs red individuals to excessive light and conclusively assessing their photoprotective functions.

While a functional analysis of genes involved in secondary metabolite biosynthesis has been performed in some instances (Jin et al., 2018; Torre et al., 2016), there is very limited information about molecular events that govern morpho-anatomical and physiological traits in red compared to green individuals (Tattini et al., 2017). Here we have extended the study of differentially expressed genes reported in Tattini et al. (2017) for purple and green basil, in which we analyzed a suite of transcription factors activated by low blue light availability and regulating key developmental processes at the leaf level. Here, special emphasis is given to a set of blue lightresponsive genes involved in shade acclimation of cyanic leaves at the photosynthetic level, which may help to 
explain conclusively the shade nature of cyanic leaves/individuals (Fig. 2). Our dataset (the complete list of DEGs is shown in Table S1 in Supporting Information) shows a number of genes responsive to low blue light (and more to low light conditions in general), which are aimed at maximizing light harvesting and that are over-expressed in purple leaves (Fig. 2). This includes a gene coding for auxilin-like J-domain protein required for chloroplast accumulation response 1 (JAC1) under low blue light (Suetsugu, Kagawa, \& Wada, 2005), thus re-locating chloroplasts perpendicular to the light flux (chloroplasts move to the periclinal cell wall). The expression levels of genes coding for Chlorophyll $a-b$ binding proteins 4 (LHCA4)and CP24 10A (CAP10A), and the niFU-like protein 3 (NIFU3) protein, all of which are involved in light harvesting in PSI and PSII (Ganadeg, Klimmek, \& Jansson, 2004; Yabe, Morimoto, Nishio, Terashima, \& Nakai 2004; Wientjes \& Croce, 2011), are also higher in cyanic leaves. This is also the case with Protein CURVATURE THYLAKOID 1A (CURT1A), which is effective in optimizing PSII photochemistry under low light conditions (Pribil et al., 2018). The need to augment light harvesting in purple leaves is also well-documented by the large expression of genes, such as Far Red Impaired Response 1 (FAR1, which is indeed negatively regulated by PHYA signaling, Lin et al., 2007) that promotes Chl biosynthesis, and Protochlorophyllide-dependent Translocon Component 52 (PTC52), which specifically sustains Chlb biosynthesis (Bartsch et al., 2008; Reinbothe et al., 2006; Tanaka, Tanaka, Tanaka, Yoshida, \& Okada, 1998).

Consistently, a range of high-light responsive genes is downregulated in red basil (Fig. 2). This includes cell division protein FtsZ homolog 1 (FtsZ1) that promotes chloroplast division and the photo-relocation of chloroplasts toward the anticlinal wall of palisade cells (so-called “chloroplast avoidance response”, Dutta et al., 2017; Kong \& Wada, 2011; Koniger, Delamaide, Marlow, \& Harris, 2008). The transcript abundance of genes that encode for proteins that either reduce the synthesis (early light-induced protein2, ELIP2, TzvetkovaChevolleau et al., 2007) or sustain the catabolism of Chl (Chlorophyllase 1, CLH1, Banaś, Labuz, Sztatelman, Gabrys, \& Fiedor, 2011), and of Chlb (NON YELLOW COLORING 1, NYC1, Horie, Ito, Kusaba, Tanaka, \& 
Tanaka, 2009), is also low in purple basil. On the other hand, the transcript abundance of a suite of genes involved in the stability and functioning of both PSI and PSII is higher in green leaves. This includes three subunits of the Photosystem I reaction center: PSAF, which enhances the efficiency of electron transfer from plastocyanin to P700 (Haldrup, Simpson \& Scheller, 2000), PSAG that downsizes the light-harvesting antenna and stabilizes the PSI core (Jensen, Rosgaard, Knoetzel \& Scheller, 2002), and PSAO, which is required to balance the distribution of excitation energy between PSI and PSII (Jensen, Haldrup, Zhang \& Scheller, 2004). The expression of a gene involved in the repair processes in PSII, the PSII stability/assembly factor HCF136 (Plöchinger et al., 2016), is also higher in green leaves than in purple. Notably, green leaves have higher expression levels of genes coding for Thioredoxin-like protein CDSP32 (CDSP32) and Plastid-Lipid-Associated protein 6 (PAP6), both reducing the oxidative stress generated in plastids because of light stress (Broin, Cuiné, Eymery, \& Rey, 2002; Lee, Kim, Landgraf, \& Apel, 2007). Finally, the expression of EXECUTER1 (EX1), a gene involved in singlet oxygeninduced chloroplast-to-nucleus retrograde signalling under excessive light (Langenkamper et al., 2011; Zhang, Apel, \&Kim 2014) is also markedly higher in green leaves as compared to red. This increase in oxidative stress signaling (sensu Foyer, Ruban, \& Noctor, 2017) displayed by green leaves adds further evidence to previous suggestions that anthocyanins are effective photoprotective pigments (Gould, 2004; Gould et al., 2010; Hughes et al., 2005, Hughes \& Smith, 2007).

The expression of genes involved in the shade avoidance responses at leaf and whole plant levels is also higher in cyanic leaves. These include three members of the PHYTOCHROME KINASE SUBSTRATE gene family (PKS1, PKS3, PKS4), which operate downstream of Phototropin1 (PHOT1) under low blue light irradiance (Lariguet et al., 2006), and act as negative regulators of phytochrome (PHY) signaling. Overexpression of $P K S$ s promotes hypocotyl elongation and leaf flattening as well, both of which being early events in shade avoidance responses (de Carbonnel et al., 2010; Lariguet et al., 2003). Other genes regulating shade avoidance responses at 
the organ and whole plant levels are also overexpressed in purple basil. This is the case with AUXIN RESPONSE 4 (AXR4), an activator of the Auxin Influx Carrier Protein 1 (AUX1, Dharmasiri et al., 2006), that induces hypocotyl elongation (Ma \& Li, 2019), and of BYPASS 1 (BPS1), whose overexpression promotes both apical dominance and leaf expansion (Lee, Parrott, Adhikari, Fraser, \& Sieburth, 2016). It is also true of LONGIFOLIA 1, LONGIFOLIA 2 and a set of EXPANSINs (EXP 1,4,8,10), all of which are known to be involved in shade avoidance responses (Christie, 2007; Sasidharan, Chinnappa, Voesenek, \& Pierik, 2008). LONGIFOLIA and EXPANSIN both promote leaf and stem elongation, by enhancing polar cell elongation at the expense of cell proliferation (Lee et al., 2018), and disrupting noncovalent bonds between cellulose microfibrils and matrix polysaccharides, respectively (Choi, Lee, Cho, \& Kende, 2003; Marowa, Ding, \& Kong, 2016).

Conversely, the transcript abundances of a range of high light responsive genes regulating developmental processes at both the leaf and the whole plant level are substantially lower in purple compared to green basil. This includes three members of the Transcription factor TCP (TCP2, TCP4, TCP24) gene family and a gene coding for L-type lectin-domain containing receptor kinase I.9 (LECRK 19), whose overexpression reduces leaf size (Bresso, Chorostecki, Rodriguez, Palatnik, \& Schommer, 2018; Bowmeester et al., 2011). Consistent with the notion that high light shapes the canopy architecture by reducing apical dominance while favoring shoot branching, green leaves display overexpression of both ARGOS (AUXIN REGULATED GENE INVOLVED IN ORGAN SIZE), d CO1-CO16 (two members of the Constans gene family), which are known to modulate the auxin signaling pathway (Hu, Xie, \& Chua, 2003; Zhang et al., 2014). An auxin-independent pathway that promotes axillary branching is also more active in green than in purple basil. This includes both DWARF27 ( $\beta$-carotene isomerase), a gene involved in the first committed step of strigolactone biosynthesis (Lin et al., 2009) and two genes, ABCG5ABCG11, coding for members of the ABC (ATP Binding Cassette transporter G family members) superfamily of 
transport proteins that are involved in the transport of strigolactones (Kretzschmar et al., 2012; Yasuno et al., 2009).

We have recently shown (Tattini et al., 2017) that a range of transcription factors that are simultaneously responsive to low both blue light irradiance and R/FR, and involved in the regulation of leaf cell fate, are largely overexpressed in high-light grown purple basil leaves as compared to corresponding green basil leaves (Tattini et al., 2017). This includes relevant members of both the Homeobox-leucine zipper protein (HD-ZIP, ATHB1, ATHB2 and ATHB12) and the basic helix-loop-helix (BHLH) families of TFs (BHLH135 and BHLH144, Fig. 2), which are known to repress cell proliferation, while at the same time promoting cell expansion (Castelain, Le Hir \& Bellini, 2012; Ciolfi et al., 2013; Hur et al., 2015; Pedmale et al., 2016). In particular, overexpression of all HDZIP members detected in our study, leads to mesophyll tissues with reduced cell number (Aoyama et al., 1995; Castelain et al., 2012; Hur et al., 2015), representing a suitable acclimation response to low light availability. This is therefore consistent with and may help conclusively explain why cyanic leaves are usually thinner, have much less compact mesophyll and lower leaf mass per area (LMA) compared to acyanic leaves (Manetas et al., 2003; Kyparissis et al., 2007; Wang, Zhou, Jiang, \& Liu, 2016), especially when grown in high light (Tattini et al., 2014).

\section{THE “PECULIAR SHADE NATURE OF CYANIC LEAVES: A PERSPECTIVE IN}

\section{ANTHOCYANIN RESEARCH}

Though cyanic leaves have a suite of morphoanatomical- and biochemical-related traits that closely resemble those usually displayed by green leaves growing in low light (true shade leaves), they also display features that are uncommon in shaded green leaves. First, the apparent quantum yield for $\mathrm{CO}_{2}$ assimilation $\left(\Phi_{\mathrm{CO} 2}\right)$ of species analysed in our study, is similar (Figs. 1A,B) or lower (Figs. 1C,D) in red compared to green leaves. This is unusual for shaded green leaves, which generally display higher apparent $\Phi_{\mathrm{CO} 2}$ than full-sun leaves at low light intensities 
(Kubiske and Pregitzer, 1996). Second, the light compensation point of red leaves occurs at higher Photosynthetic Photon Flux Density (PPFD) compared to green leaves in three out of the four A:PPFD curves in Fig. 3, whereas shade leaves usually display lower light compensation points than those acclimated to full sunlight (Givnish, Montgomery, \& Goldstein, 2004 ). This likely due to red leaves having higher rates of dark respiration (RD) compared to green leaves (Ranjan et al., 2014; Yu, Zhang, Zheng, Huang, \& Peng, 2019), whereas the reverse is usually observed in green shaded leaves (Kubiske and Pregitzer, 1996; Poorter et al. 2019). Third, while shaded green leaves typically saturate photosynthesis at lower PPFD compared to leaves growing in full sun (due to lower Rubisco content per unit leaf area, Seeman, 1989), photosynthesis in cyanic leaves saturates at very similar or even higher PPFD than do the green counterparts (Fig. 3). This is because the epidermal anthocyanin filter effectively absorbs blue/red photons that are most efficient for $\mathrm{CO}_{2}$ fixation. This explains why red leaves have higher photosynthesis during the central hours of the day compared to green leaves (Tattini et al., 2017; Fini et al., unpublished results) and, in addition, offers clear evidence for an effective photoprotective function of anthocyanins. We also observe that stomatal conductance in red leaves is higher or very similar compared to that of green leaves in some instances (Liakopoulos et al., 2006; Tattini et al., 2014, 2017). This is also unusual for true shade leaves, in which the excess of green compared to blue (and red) photons opposes the opening and the development of stomata (Chen, Xiao, Li, \& Ni, 2012; Poorter et al., 2019). However, cyanic leaves sense both higher blue/green and red/green ratio compared to shaded green leaves, and this may promote stomata opening (Smith et al., 2017). This matter deserves further investigation aimed specifically at evaluating the relative contribution of blue, green and red/far red signals (Merzlyak et al., 2008) perceived by cyanic leaves, to the downstream molecular events regulating the development and the aperture of stomata (Inoue \& Kinoshita, 2017; Hiyama et al., 2017; Kang, Lian, Wang, Huang, \& Yang, 2009). 
The profound morpho-anatomical adjustments imposed by the epidermal anthocyanin shield complicates the analysis of the "photosynthetic performance" of cyanic vs acyanic leaves and, hence, of the photoprotective role of anthocyanins. For instance, Tattini et al. (2017) have shown that mesophyll conductance to $\mathrm{CO}_{2}\left(\mathrm{~g}_{\mathrm{m}}\right)$ is substantially lower in purple than in green basil leaves growing in full sunlight (similar results have been observed in Acer platanoides, Fini unpublished data). Actually, the conductance to $\mathrm{CO}_{2}$ diffusion is usually lower in the mesophyll of shaded green leaves than in those exposed to full sun (Campany, Tjoelker, von Cammer, \& Duursma, 2016; Peguero-Pina et al., 2016). Though the anatomical features of shaded leaves might appear as optimally suited to facilitate $\mathrm{CO}_{2}$ diffusion across the mesophyll, $\mathrm{g}_{\mathrm{m}}$ is only partially determined by leaf morpho-anatomical traits: proteins such as carbonic anhydrase and aquaporins, may have a strong impact on mesophyll conductance to $\mathrm{CO}_{2}$ (Hanba et al., 2004; Fini et al., 2016; Peguero-Pina et al., 2016). For instance, both the biosynthesis and the activity of carbonic anhydrase is strongly light dependent (Tiwari et al., 2006), and the expression of aquaporins is low in leaves growing in the shade, especially under blue light deprivation (Ben Baaziz et al., 2012). This may help explain the general positive scaling of $g_{m}$ with light irradiance in a range of species (Flexas et al., 2008), as well as the lower $g_{m}$ observed in cyanic leaves (Tattini et al., 2017; Fini unpublished data). We finally note that both the chloroplast (chloroplasts move toward periclinal cell wall, Wada, 2016) and mesophyll areas exposed to intercellular airspaces may decrease in cyanic leaves because of shade acclimation, thus further decreasing gm ni et al., 2016). We hypothesize that the wide range of anatomical adjustments because of low light availability force cyanic leaves to have "unusually high” stomatal conductance to partially counter the larger limitation to $\mathrm{CO}_{2}$ diffusion through the mesophyll (Fini et al., 2016; Tattini et al., 2017). This may also explain why the drawdown from actual (calculated from response curves of $A_{N}$ to changes in chloroplast $\mathrm{CO}_{2}$ concentration, $\mathrm{A}_{N} / \mathrm{C}_{c}$ curves) to apparent (calculated from response curves of $A_{N}$ to changes in intercellular $\mathrm{CO}_{2}$ concentration, $\mathrm{A}_{N} / \mathrm{C}_{\mathrm{i}}$ curves) carboxylation efficiency ( $\mathrm{V}_{c, \max }$ ) was markedly higher in purple as compared to green basil leaves (Tattini et al., 
2017). The lower carboxylation efficiency of red compared to the green counterparts reported in previous studies (Carpenter, Keidel, Pihl, \& Hughes, 2014; Nikoforou et al., Ranjan et al., 2014) may merit extensive re-evaluation. In turn, this poses serious methodological issues regarding the effective photoprotective potential of cyanic vs acyanic leaves. We recall that photoprotection, a qualitative parameter in its nature, closely relates to photoinhibition and, hence is suitably quantified by high light-induced depression of photosynthesis, rather than photosynthesis per se. However, in most studies the degree of photoinhibition in cyanic vs acyanic leaves has been estimated through light-induced declines in $\mathrm{F}_{\mathrm{v}} / \mathrm{F}_{\mathrm{m}}\left(\Delta \mathrm{F}_{\mathrm{v}} / \mathrm{F}_{\mathrm{m}}\right)$ and/or $\Phi_{\text {PSII }}\left(\Delta \Phi_{\text {PSII }}\right)$. Because $\mathrm{g}_{\mathrm{s}}$, and particularly $\mathrm{g}_{\mathrm{m}}$ are major constraints to photosynthesis, especially under high light irradiance (Niinemets, Diaz-Espejo, Flexas, Galmés, \& Warren, 2009), light-induced changes in $\mathrm{F}_{\mathrm{v}} / \mathrm{F}_{\mathrm{m}}$ and $\Phi_{\mathrm{PSII}}$ between cyanic vs. acyanic leaves are not optimally suited to describe their relative photosynthetic performance. We conclude that quantifying the relative contribution of diffusional limitations to photosynthesis in cyanic vs acyanic leaves long-exposed to excessive light (when photoprotection really makes sense) will significantly improve our understanding on the actual photoprotective role(s) of anthocyanins.

\section{ACKNOLEDGMENTS}

We thank Dr. Alessandra Ferrandino (Department of Agricultural, Forest and Food Sciences, University of Turin) for providing the absorption spectra of isolated anthocyanins reported in Fig. S1. We also thank Dr. Emily Rose Palm (Department of Agriculture, Food, Environment and Forestry, University of Florence) for the critical reading of the MS.

\section{CONFLICT OF INTEREST}

All authors declare that they have no conflict of interest. This article does not contain any studies with human participants or animals performed by any of the authors. 
This article is protected by copyright. All rights reserved. 


\section{References}

Agati, M. \& Tattini, M. (2010). Multiple functional roles of flavonoids in photoprotection. New Phytologist, 186, 786-793.

Agati, G., Cerovic, Z.G., Pinelli, P., \& Tattini, M. (2011). Light-induced accumulation of ortho-dihydroxylated flavonoids as non-destructively monitored by chlorophyll fluorescence excitation techniques. Environmental and Experimental Botany, 73, 3-9.

Aoyama, T., Dong, C., Wu, Y., Carabelli, M., Sessa, G., Ruberti, I., Morelli, G., Chua, N. (1995) Ectopic expression of the Arabidopsis transcriptional activator Athb-1 alters leaf cell fate in tobacco. Plant Cell 7, 1773-1785.

Ballaré, C.L., \& Pierik, R. (2017). The shade-avoidance syndrome: multiple signals and ecological consequences. Plant Cell \& Environment, 40, 2530-2543.

Ballaré, C.L., Scopel, A., \& Sanchez, R.A. (1990). Far-red radiation reflected from adjacent leaves: An early signal of competition in plant canopies. Science, 247, 329-332.

Banaś, A.K., Labuz, J., Sztatelman, O., Gabryś, H., \& Fiedor, L. (2011). Expression of enzymes involved in chlorophyll catabolism in Arabidopsis is light controlled. Plant Physiology, 157, 1497-1504.

Bartsch, S., Monnet, J., Selbach, K., Quigley, F., Gray, J., von Wettstein, D., Reinbothe, S., \& Reinbothe, C. (2008). Three thioredoxin targets in the inner envelope membrane of chloroplasts function in protein import and chlorophyll metabolism. Proceedings of the National Academy of Science of the United States of America, 105, 4933-4938.

Ben Baaziz, K., Lopez, D., Rabot, A., Combes, D., Gousset, A., Bouzid, S., Cochard, H., .........Venisse, J.-S. (2012). Light-mediated $\mathrm{K}_{\text {leaf }}$ induction and contribution of both the PIP1s and PIP2s aquaporins in five tree species: walnut (Juglans regia) case study. Tree Physiology, 32, 423-434. 
Boardman, N.K. (1977). Comparative photosynthesis of shade and sun plant. Annual Review of Plant Physiology 28, 355-377.

Bowmeester, K., de Sain, M., Weide, R., Gouget, A., Klamer, S., Nanut, H, \& Govers, F. (2011). The Lectin receptor kinase LecRK-I.9 is a novel Phytophthora resistance component and a potential host target for a RXLR effector. PLoS Pathogens, 7, e1001327.

Bresso, E.G., Chorostecki, U., Rodriguez, R.E., Palatnik, J.F., \& Schommer, C. (2018). Spatial control of gene expression by miR319-regulated TCP transcription factors in leaf development. Plant Physiology, 176, 16941708.

Broin, M., Cuiné, S., Eymery, F., \& Rey, P. (2002). The plastidic 2-cysteine peroxiredoxin is a target for a thioredoxin involved in the protection of the photosynthetic apparatus against oxidative damage. Plant Cell $14,1417-1432$.

Campany, C.E., Tjoelker, M.G., von Caemmerer, S., \& Duursma, MA. (2016). Coupled response of stomatal and mesophyll conductance to light enhances photosynthesis of shade leaves under sunflecks. Plant Cell \& Environment, 39, 2762-2773.

Castelain, M., Le Hir, R., \& Bellini, C. (2012). The non-DNA-binding bHLH transcription factor PRE3/bHLH135/ATBS1/TMO7 is involved in the regulation of light signaling pathway in Arabidopsis. Physiologia Plantarum, 145, 450-460.

Carpenter, K.L., Keidel, T.S., Pihl, M.C., Hughes, N.M. (2014). Support for a photoprotective function of winter leaf reddening in nitrogen-deficient individuals of Lonicera japonica. Molecules, 19, 17810-17828.

Chalker-Scott, L. (1999). Environmental significance of anthocyanins in plant stress responses. Photochemistry and Photobiology, 70, 1-9. 
Chen, C., Xiao, Y., Li, X., \& Ni, M. 2012. Light-regulated stomatal aperture in Arabidopsis. Molecular Plant, 5, 566-572.

Choi, D., Lee, Y., Cho, H.-T., \& Kende, H. (2003). Regulation of expansin gene expression affects growth and development in transgenic rice plants. Plant Cell, 15, 1386-1398.

Christie, J.M. (2007). Phototropin blue-light receptors. Annual Review of Plant Biology, 58, 21-45.

Christopher, D.A., \& Mullet, J.E. (1994) Separate photosensory pathways co-regulates blue light/ultraviolet-Aactivated psbD-psbC transcription and light-induced D2 and CP43 degradation in barley (Hordeum vulgare) chloroplasts. Plant Physiology, 104, 1119- 1129

Ciolfi, A., Sessa, G., Sassi, M., Possenti, M., Salvucci, S., Carabelli, M., Morelli, G., \& Ruberti, I. (2013). Dynamics of the shade-avoidance response in Arabidopsis. Plant Physiology, 163, 331-353.

Cooney, L.J., Schaefer, H.M., Logan, B.A., Cox, B., \& Gould, K.S. (2015). Functional significance of anthocyanins in peduncles of Sambucus nigra. Environmental and Experimental Botany, 119, 18-26.

de Carbonnel, M., Davis, P., Roelfsema, M.R.G., Inoue, S.-I., Schepens, I., Lariguet, P., Geisler, M., .....Fankhauser, C. (2010). The Arabidopsis PHYTOCHROME KINASE SUBSTRATE2 protein is a phototropin signaling element that regulates leaf flattening and leaf positioning. Plant Physiology, 152, 13911405.

Dharmasiri, S., Swarup, R., Mockaitis, K., Dharmasiri, N., Kumar Singh, S., Marchant, A., Sandberg, G. .......Estelle, M. (2006). AXR4 is required for localization of the auxin influx facilitator AUX1. Science. 312, $1218-1220$.

Dhingra, A., Dies, B.H., Lehner, K.R., \& Folta, K.M. (2006). Green light adjusts the plastid transcriptome during early photomorphogenic development. Plant Physiology, 142, 1256-1266. 
Drumm-Herrel, H., \& Mohr, H. (1985). Photosensitivity of seedlings differing in their potential to synthesize anthocyanin. Physiologia Plantarum, 64, 60-66.

Dutta, S., Cruz, J.A., Imran, S.M., Chen, J., Kramer, D.M., Osteryoung, K.W. (2017). Variations in chloroplast movement and chlorophyll fluorescence among chloroplast division mutants under light stress. Journal of Experimental Botany, 68, 3541-3555.

Fankhauser, C., \& Batschauer, A. (2016). Shadow on the plant: A strategy to exit. Cell, 164, 15-17.

Feild, T.S., Lee, D.W. and Holbrook, N.M., 2001. Why leaves turn red in autumn. The role of anthocyanins in senescing leaves of red-osier dogwood. Plant Physiology, 127, 566-574.

Fini, A., Loreto, F., Tattini, M., Giordano, C., Ferrini, F., Brunetti, C., \& Centritto, M. (2016). Mesophyll conductance plays a central role in leaf functioning of Oleaceae species exposed to contrasting sunlight irradiance. Physiologia Plantarum 157, 54-68.

Flexas, J., Ribas-Carbó, M., Díaz-Espejo, A., Galmés, J. \& Medrano, H. (2008). Mesophyll conductance to $\mathrm{CO}_{2}$ : current knowledge and future prospects. Plant Cell \& Environment 31, 602-621.

Folta, K.M., \& Kaufman, L.S. (2003). Phototropin 1 is required for high-fluence blue-light-mediated mRNA destabilization. Plant Molecular Biology, 51, 609-618.

Folta, K.M., \& Maruhnich, S.A. (2007). Green light: a signal to slow down or stop. Journal of Experimental Botany, 58, 3099-3111.

Foyer, C.H., Ruban, A.V., \& Noctor, G. (2017). Viewing oxidative stress through the lens of oxidative signalling rather than damage. Biochemical Journal, 474, 877-883.

Franklin, K.A. (2008). Shade avoidance. New Phytologist, 179, 930-944.

Ganadeg, U., Klimmek, F., \& Jansson, S. (2004). Lhca5- an LHC-type protein associated with photosystem I. Plant Molecular Biology, 54, 641-651. 
Givnish, T.J., Montgomery, R.A. \& Goldstein, G. (2004). Adaptive radiation of photosynthetic physiology in the Hawaiian lobeliads: light regimes, static light responses, and whole plant compensation points. American Journal of Botany, 91, 228-246.

Gould, K.S., Vogelmann, T.C., Han, T., \& Clearwater, M.J. (2002). Profiles of photosynthesis within red and green leaves of Quintinia serrata. Physiologia Plantarum, 116, 127-133.

Gould, K.S. (2004). Nature's Swiss army knife: the diverse protective roles of anthocyanins in leaves. Journal of Biomedicine and Biotechnology, 2004, 314-320.

Gould, K.S., Dudle, D.A., \& Neufeld, H.S. (2010). Why some stems are red: cauline anthocyanins shield photosystem II against high light stress. Journal of Experimental Botany, 61, 2707-2717.

Gould, K.S., Jay-Allemand, C., Logan, B.A., Baissac, Y., \& Bidel. L.P.R. (2018). When are foliar anthocyanins useful to plants? Re-evaluation of the photoprotection hypothesis using Arabidopsis thaliana mutants that differ in anthocyanin accumulation. Environmental and Experimental Botany, 154, 11-22.

Halbwirth, H. (2010). The creation and physiological relevance of divergent hydroxylation patterns in the flavonoid pathway. International Journal of Molecular Sciences, 11, 595-621.

Haldrup, A., Simpson, D.J., \& Scheller, H.W. (2000) Down-regulation of the PSI-F Subunit of Photosystem I (PSI) in Arabidopsis thaliana: The PSI-F subunit is essential for photoautotrophic growth and contributes to antenna function. Journal of Biological Chemistry, 275, 31211-31218.

Hanba Y.T., Shibasaka M., Hayashi Y., Hayakawa T., Kasamo K.,Terashima I.\& Katsuhara M.(2004) Overexpression of the bar-ley aquaporin HvPIP2; 1 increases internal $\mathrm{CO}_{2}$ conductance and $\mathrm{CO}_{2}$ assimilation in the leaves of transgenic rice plants. Plant \& Cell Physiology 45, 521-529. 
Hatier, J.-H. B., Clearwater, M.J., \& Gould, K.S. (2013). The functional significance of black-pigmented leaves: photosynthesis, photoprotection and productivity in Ophiopogon planiscapus 'Nigrescens'. PLoS ONE, 8, e67850.

Hayes, S., Velanis, C.N., Jenkins, G.I., Franklin, K.A. (2014). UV-B detected by the UVR8 photoreceptor antagonizes auxin signaling and plant shade avoidance. Proceedings of the National Academy of Sciences of the United States of America, 111, 11894-11899.

Hiyama, A., Takemya, A., Munemsa, S., Okumi, E., Sugiyama, N., Tada, Y., Murata, Y., \& Shimazaki, K.-i. (2017). Blue light and $\mathrm{CO}_{2}$ signals converge to regulate light-induced stomatal opening. Nature Communications, 8, 1284.

Horie, Y., Ito. H., Kusaba. M., Tanaka, R., \& Tanaka, A. (2009). Participation of chlorophyll $b$ reductase in the initial step of the degradation of light-harvesting chlorophyll a/b-protein complexes in Arabidopsis. Journal of Biological Chemistry, 284, 17449-17456.

Horton, P. (2012). Optimization of light harvesting and photoprotection: molecular mechanisms and physiological consequences. Philosophical Transactions of the Royal Society London B Biological Sciences, 367, 34553465.

Hu, Y., Xie, Q., \& Chua, N.-H. (2003). The Arabidopsis auxin-inducible gene ARGOS controls lateral organ size. Plant Cell, 15, 1951-1961.

Hughes, N.M., Neufeld, H.S., \& Burkey, K.O. (2005). Functional role of anthocyanins in high-light winter leaves of the evergreen herb Galax urceolata. New Phytologist, 168, 575-587.

Hughes, N.M., \& Smith, W.K. (2007). Attenuation of incident light in Galax urceolata (Diapensiaceae): concerted influence of adaxial and abaxial anthocyanic layers on photoprotection. American Journal of Botany, 94, 784-790. 
Hughes, N.M. (2011). Winter leaf reddening in ‘evergreen’ species. New Phytologist, 190, 573-581.

Hughes NM, Carpenter KL, Keidel TS, Miller CN, Waters, M.N., \& Smith WK. 2014. Photosynthetic costs and benefits of adaxial versus abaxial anthocyanins in Colocasia esculenta 'Mojito'. Planta, 240, 971-81.

Hur, Y.S., Um, J.H., Kim, S., Kim, K., Park, H.J., Lim, J.S., Kim, W.Y., .....Cheon, C.I. (2015). Arabidopsis thaliana homeobox 12 (ATHB12), a homeodomain-leucine zipper protein, regulates leaf growth by promoting cell expansion and endoreduplication. New Phytologist, 205, 316-328.

Inoue, S.-i., \& Kinoshita, T. (2017). Blue light regulation of stomatal opening and the plasma membrane $\mathrm{H}^{+}-$ ATPase. Plant Physiology, 174, 531-538.

Jensen, P.E., Rosgaard, L., Knoetzel, J., \& Scheller, H.V. (2002). Photosystem I activity is increased in the absence of the PSI-G subunit. Journal of Biological Chemistry 277, 2798-2803.

Jensen, P.E., Haldrup, A., Zhang, S., \& Scheller, H.V. (2004). The PSI-O subunit of plant photosystem I is involved in balancing the excitation pressure between the two photosystems. Journal of Biological Chemistry 279, 24212-24217.

Jiao, Y., Yang, H., Ma, L., Sun, N., Yu, H., Liu, T., Gao, Y., ......Deng, X.W. (2003). A genome-wide analysis of blue-light regulation of Arabidopsis transcription factor gene expression during seedling development. Plant Physiology, 133, 1480-1493.

Jin, S.-W., Rahim, M.A., Afrin, K.S., Park, J.-I., Kang, J.-G., \& Nou, I.-S. (2018). Transcriptome profiling of two contrasting ornamental cabbage (Brassica oleracea var. acephala) lines provides insights into purple and white inner leaf pigmentation. BMC Genomics, 19, 797.

Jordheim, M., Calcott, K., Gould, K.S., Davies, K.M., Schwinn, K.E., \& Andersen, Ø.M. (2016). High concentrations of aromatic acylated anthocyanins found in cauline hairs in Plectranthus ciliates. Phytochemistry, 128, 27-34. 
Jeon, J., Kim, J.K., Kim, H.R., Kim, Y.J., Park, Y.J., Kim, S.J., Kim, C., \& Park, S.U. (2018). Transcriptome analysis and metabolic profiling of green and red kale (Brassica oleracea var. acephala) seedlings. Food Chemistry, 241: 7-13.

Kal, A.J., van Zonneveld, A.J., Benes, V., van den Berg, M., Koerkamp, M.G., Albermann, K., Strack, N. ..... Tabak, H.F. (1999). Dynamics of gene expression revealed by comparison of serial analysis of gene expression transcript profiles from yeast grown on two different carbon sources. Molecular Biology of the Cell 10, 1859-1872.

Kang, C.-Y., Lian, H.-L., Wang, F.-F., Huang, J.-R., \& Yang, H.Q. (2009). Cryptochromes, phytochromes, and COP1 regulate light-controlled stomatal development in Arabidopsis. Plant Cell, 21, 2624-2641.

Keuskamp, D.H., Keller, M.M., Ballaré, C.L., \& Pierik, R. (2012). Blue light regulated shade avoidance. Plant Signaling \& Behavior, 7, 514-517.

Kong, S.G., \& Wada, M. (2011). New insights into dynamic actin-based chloroplast photorelocation movement. Molecular Plant, 4, 771-781.

Königer, M., Delamaide, J.A., Marlow, E.D., \& Harris GC. (2008). Arabidopsis thaliana leaves with altered chloroplast numbers and chloroplast movement exhibit impaired adjustments to both low and high light. Journal of Experimental Botany, 59, 2285-2297.

Kretzschmar, T., Kohlen, W., Sasse, K., Borghi, L., Schlegel, M., Bachelier, J.B., Reinhardt, D., .....Martinoia E. (2012). A petunia ABC protein controls strigolactone-dependent symbiotic signalling and branching. Nature, 483, 341-344.

Kubiske, M.E., \& Pregitzer, K.S. (1996). Effects of elevated $\mathrm{CO}_{2}$ and light availability on the photosynthetic light response of trees of contrasting shade tolerance. Tree Physiology, 16, 351-358. 
Kyparissis, A., Grammatikopoulos, G., \& Manetas, Y. (2007). Leaf morphological and physiological adjustments to the spectrally selective shade imposed by anthocyanins in Prunus cerasifera. Tree Physiology, 27, 849857.

Kytridis, V.P., Karageorgou, P., Levizou, E., \& Manetas, Y. (2008). Intraspecies variation in transient accumulation of leaf anthocyanins in Cistus creticus during winter: evidence that anthocyanins may compensate for an inherent photosynthetic and photoprotective inferiority of the red-leaf phenotype. Journal of Plant Physiology, 165, 952-959.

Landi, M., Guidi, L., Pardossi, A., Tattini, M., \& Gould, K.S. (2014). Photoprotection by foliar anthocyanins mitigates effects of boron toxicity in sweet basil (Ocimum basilicum). Planta, 240, 941-953.

Landi, M., Tattini, M., \& Gould, K.S. (2015). Multiple functional roles of anthocyanins in plant-environment interactions. Environmental \& Experimental Botany, 119, 54-62.

Landi, M. Zivcak, M., Sytar, O., Brestic, M., Allakhverdiev, S.I. (2020). Plasticity of photosynthetic processes and the accumulation of secondary metabolites in plants in response to monochromatic light environments: A review. Biochimica et Biophysica Acta-Bioenergetics, 1861, 148131.

Langenkämper, G., Manac’h, N., Broin, M., Cuiné, S., Becuwe, N., Kuntz, M., \& Rey, P. (2011). Accumulation of plastid lipid-associated proteins (fibrillin/CDSP34) upon oxidative stress, ageing and biotic stress in Solanaceae and in response to drought in other species. Journal of Experimental Botany, 52, 1545-1554.

Lariguet, P., Boccalandro, H.E., Alonso, J.M., Ecker, J.R., Chory, J., Casal, J.J., \& Fankhauser, C. (2003). A growth regulatory loop that provides homeostasis to phytochrome A signaling. Plant Cell, 15, 2966-2978.

Lariguet, P., Schepens, I., Hodgson, D., Pedmale, U.V., Trevisan, M., Kami, C., de Carbonnel, M., ......Fankhauser, C. (2006). PHYTOCHROME KINASE SUBSTRATE 1 is a phototropin 1 binding protein required for phototropism. Proceedings of the National Academy of Sciences USA, 103, 10134-10139. 
Lee, D.K., Parrott, D.L., Adhikari, E., Fraser, N. \& Sieburth, L.E. (2016). The mobile Bypass signal arrests shoot growth by disrupting shoot apical meristem maintenance, cytokinin signaling, and WUS transcription factor expression. Plant Physiology, 171, 2178-2190.

Lee, K.P., Kim, C., Landgraf, F., \& Apel K. (2007). EXECUTER1- and EXECUTER2-dependent transfer of stress-related signals from the plastid to the nucleus of Arabidopsis thaliana. Proceedings of the National Academy of Sciences of the United States of America, 104, 10270-10275.

Lee, Y.K., Rhee, J.Y., Lee, S.H., Park, S.J., Segami, S., Maeshima, M., \& Choi, G. (2018). Functionally redundant LNG3 and LNG4 genes regulate turgor-driven polar cell elongation through activation of XTH17 and XTH24. Plant Molecular Biology, 97, 33-36.

Liakopoulos, G., Nikolopoulos, D., Klouvatou A., Vekkos, K.A., Manetas. Y., \& Karabourniotis, G. (2006). The photoprotective role of epidermal anthocyanins and surface pubescence in young leaves of grapevine (Vitis vinifera). Annals of Botany, 98, 257-265.

Lin R., Ding L., Casola C., Ripoll D. R., Feschotte C., Wang H. (2007). Transposase-derived transcription factors regulate light signaling in Arabidopsis. Science 318, 1302-1305.

Lin, H., Wang, R., Qian, Q., Yan, M., Meng, X., Fu, Z., Yan, C. .........Wang, Y. (2009). DWARF27, an ironcontaining protein required for the biosynthesis of strigolactones, regulates rice tiller bud outgrowth. Plant Cell, 21, 1512-1525.

Logan, B.A., Stafstrom, W.C., Walsh, M.J., Reblin, J.S., \& Gould, K.S. (2015). Examining the photoprotection hypothesis for adaxial foliar anthocyanin accumulation by revisiting comparisons of green- and red-leafed varieties of coleus (Solenostemon scutellarioides). Photosynthesis Research, 124, 267-274.

Long, S.P., Humphries, S., \& Falkowski, P.G. (1994). Photoinhibition of photosynthesis in nature. Annual Review of Plant Physiology and Plant Molecular Biology, 45, 633-662. 
Loreto, F., Tsonev, T., \& Centritto, M. (2009). The impact of blue light on leaf mesophyll conductance. Journal of Experimental Botany, 60, 2283-2290.

Ma, L., \& Li, G. (2019). Auxin-dependent cell elongation during the shade avoidance response. Frontiers in Plant Sciences 10, 914.

Manetas, Y., Petropoulou, Y., Psara, G.K., \& Drinia, A. (2003). Exposed red (anthocyanic) leaves of Quercus coccifera display shade characteristics. Functional Plant Biology, 30, 265-270.

Manetas, Y. (2006). Why some leaves are anthocyanic and why most anthocyanic leaves are red? Flora, 201, 163177.

Marowa, P., Ding, A., \& Kong, Y. (2016). Expansins: roles in plant growth and potential applications in crop improvement. Plant Cell Reports, 35, 949-965.

Mazza, C.A., \& Ballaré, C.L. (2015). Photoreceptors UVR8 and phytochrome B cooperate to optimize plant growth and defense in patchy canopies. New Phytologist, 207, 4-9.

Mazza, G., \& Brouillard, R. (1990). The mechanism of co-pigmentation of anthocyanins in aqueous solutions. Phytochemistry, 29, 1097-1102.

McClure JW. 1975. Physiology and functions of flavonoids. In: Harborne JB, Mabry TJ, Mabry H, eds. The Flavonoids London, UK: Chapman 81 Hall Ltd, 970-1055.

Menzies, I.J., Youard, L.W., Lord, J.M., Carpenter, K.L., van Klink, J.W., Perry, N.B., Schaefer, H.M. \& Gould, K.S. (2015). Leaf colour polymorphisms: a balance between plant defence and photosynthesis. Journal of Ecology, 104, 104-113.

Merzlyak, M.N., Chivkunova, O.B., Solovchenko, A.E., \& Naqvi, K.R. (2008). Light absorption by anthocyanins in juvenile, stressed, and senescing leaves. Journal of Experimental Botany, 59, 3903-3911. 
Mortazavi, A., Williams, B.A., McCue, K., Schaeffer, L., \& Wold, B. (2008). Mapping and quantifying mammalian transcriptomes by RNA-Seq. Nature Methods 5, 621-628.

Nakamura, T., Furuhashi, Y., Hasegawa, K., Hashimoto, H., Watanabe, K., Obokata, J, Sugita, M., \& Sugiura, M. (2003). Array-based analysis on tobacco plastid transcripts: preparation of a genomic microarray containing all genes and all intergenic regions. Plant and Cell Physiology, 44, 861-867.

Neill, S., \& Gould, K.S. (1999). Optical properties of leaves in relation to anthocyanin concentration and distribution. Canadian Journal of Botany, 77, 1777-1782.

Niinemets, Ü., Diaz-Espejo, A, Flexas, J., Galmés, J., Warren, C.R. (2009). Role of mesophyll diffusion conductance in constraining potential photosynthetic productivity in the field. Journal of Experimental Botany 60, 2249-2270.

Nikoforou, C., Nikopoulos, D., \& Manetas, Y. (2011). The winter-red-leaf syndrome in Pistacia lentiscus: evidence that the anthocyanic phenotype suffers from nitrogen deficiency, low carboxylation efficiency and high risk of photoinhibition. Journal of Plant Physiology, 168, 2184-2187.

Pedmale, U.V., Huang, S.C., Zander, M., Cole, B.J., Hetzel, J., Ljung, K., Reis, P.A.B., ...... Chory, J. (2016). Cryptochromes interact directly with PIFs to control plant growth in limiting blue light. Cell, 164, 233-245.

Peguero-Pina, J.J., Sancho-Knapik, D., Flexas, J., Galmés, J., Niinemets, Ü., \& Gil-Pelegrín, E. (2016). Light acclimation of photosynthesis in two closely related firs (Abies pinsapo Boiss. and Abies alba Mill.): the role of leaf anatomy and mesophyll conductance to $\mathrm{CO}_{2}$. Tree Physiology, 36, 300-310.

Plöchinger, M., Schwenkert, S., von Sydow, L., Schröder, W.P., \& Meurer, J. (2016). Functional update of the auxiliary proteins PsbW, PsbY, HCF136, PsbN, TerC and ALB3 in maintenance and assembly of PSII. Frontiers in Plant Science 7, 423. 
Poorter, H., Niinemets, Ū., Ntagkas, N., Siebankäs, A., Mäenpää, M., Matsubara, S., \& Pons, T.L. (2019). A metaanalysis of plant responses to light intensity for 70 traits ranging from molecules to whole plant performance. New Phytologist, 223, 1073-1105.

Pribil, M., Sandoval-Ibáñez, O., Xu, W., Sharma, A., Labs, M., Liu, Q., Galgenmüller, K., .......Leister, D. (2018). Fine-tuning of photosynthesis requires CURVATURE THYLAKOID1-mediated thylakoid plasticity. Plant Physiology, 176, 2351-2364.

Ranjan, S., Singh, R., Singh, M., Pathre, U.V., \& Shirke, P.A. (2014). Characterizing photoinhibition and photosynthesis in juvenile-red versus mature-green leaves of Jatropha curcas L. Plant Physiology and Biochemistry, 79, 48-59.

Rasulov, B., Bichele, I., Laisk, A., \& Niinemets, Ü. (2014). Competition between isoprene emission and pigment synthesis during leaf development in aspen. Plant Cell \& Environment, 37, 724-741.

Rein, M.J., Ollilainen, V., Vahermo, M., Yli-Kauhaluoma, J., \& Heinonen, M. (2005). Identification of novel pyranoanthocyanins in berry juices. European Food Research and Technology, 220, 239-244.

Reinbothe, C., Bartsch, S., Eggink, L.L., Hoober, J.K., Brusslan, J., Andrade-Paz, R., Monnet, J., \& Reinbothe, S. (2006). A role for chlorophyllide $a$ oxygenase in the regulated import and stabilization of light-harvesting chlorophyll $a / b$ proteins. Proceeding of the National Academy of Sciences of the United States of America, 103, 4777-4782.

Ruban, A.V. (2018). Light harvesting control in plants. FEBS Letters, 592, 3030-3039.

Sasidharan, R., Chinnappa, C.C., Voesenek, L.A.C.J., \& Pierik, R. (2008). The regulation of cell wall extensibility during shade avoidance: a study using two contrasting ecotypes of Stellaria longipes. Plant Physiology, 148, 1557-1569. 
Seeman, J.R. (1989). Light adaptation/acclimation of photosynthesis and the regulation of Ribulose-1,5bisphosphate carboxylase activity in sun and shade plants. Plant Physiology, 91, 376-389.

Sellaro, R., Crepy, M., Trupkin, S.A., Karayekov, E., Buchovsky, A.S., Rossi, C., \& Casal, J.J. (2010). Cryptochrome as a sensor of the blue/green ratio of natural radiation in Arabidopsis. Plant Physiology, 154, 401-409.

Smith, H.L., McAuslan, L., \& Murchie, E.H. (2017). Don’t ignore the green light: exploring diverse roles in plant processes. Journal of Experimental Botany, 68, 2099-2110.

Steyn, W.J., Wand, S.J.E., Holcroft, D.M., \& Jacobs, G. (2002). Anthocyanins in vegetative tissues: a proposed unified function in photoprotection. New Phytologist, 155, 349-361.

Suetsugu, N., Kagawa, T., \& Wada, M. (2005). An auxilin-like J-domain protein, JAC1, regulates phototropinmediated chloroplast movement in Arabidopsis. Plant Physiology, 139, 151-162.

Takahashi, S., Milward, S.E., Yamori, W., Evans, J.R., Hillier, W., \& Badger, M.R. (2010). The solar action spectrum of Photosystem II damage. Plant Physiology 153: 988-993.

Tanaka, A., Ito, H., Tanaka, R., Tanaka, N.K., Yoshida, K., \& Okada, K. (1998). Chlorophyll a Oxygenase (CAO) is involved in Chlorophyll $b$ Formation from Chlorophyll a. Proceedings of the National Academy of Sciences of the United States of America, 95, 12719-12723.

Tattini, M., Landi, M., Brunetti, C., Giordano, C., Remorini, D., Gould, K.S., \& Guidi, L. (2014). Epidermal coumaroyl anthocyanins protect sweet basil against excess light stress: multiple consequences of light attenuation. Physiologia Plantarum 152: 585-598.

Tattini, M., Sebastiani, F., Brunetti, C., Fini, A., Torre, S., Gori, A., Centritto, M., ......Guidi, L. (2017). Dissecting molecular and physiological response mechanisms to high solar radiation in cyanic and acyanic leaves: a case study on red and green basil. Journal of Experimental Botany, 68, 2425-2437. 
Terashima, I, Fujita, T., Inoue, T., Chow, W.S., \& Oguchi, R. (2009). Green light drives leaf photosynthesis more efficiently than red light in strong white light: revisiting the enigmatic question of why leaves are green. Plant \& Cell Physiology, 50, 684-697.

Tiwari, A., Kumar, P., Chawhaan, P.H., Singh, S., \& Ansari, S.A. (2006). Carbonic anhydrase in Tectona grandis: kinetics, stability, isozyme analysis and relationship with photosynthesis. Tree Physiology, 26, 1067-1073.

Torre, S., Tattini, M., Brunetti, C., Guidi, L., Gori, A., Marzano, C., Landi, M., \& Sebastiani, F. (2016). De novo assembly and comparative transcriptome analyses of red and green morphs of sweet basil grown in full sunlight. PLoS ONE 11: e0160370.

Trouilas, P., Sancho-Garcia. J.C., De Freitas, V., Gierschner, J., Otyepka, M., \& Dangles, O. (2016). Stabilizing and modulating color by copigmentation: Insights from theory and experiment. Chemical Reviews, 116, 49374982.

Tzvetkova-Chevolleau, T., Franck, F., Alawady, A.E., Dall’Osto, L., Carrière, F., Bassi, R., Grimm, B., ......Havaux, M. (2007). The light stress-induced protein ELIP2 is a regulator of chlorophyll synthesis in Arabidopsis thaliana. Plant Journal, 50, 795-809.

Wada, M. (2016). Chloroplast and nuclear photorelocation movements. Proceedings of the Japan Academy, Series B Physical and Biological Sciences, 92, 387-411.

Wang, Y., \& Folta, K.M. (2013). Contribution of green light to plant growth and development. America Journal of Botany, 100,: 70-78.

Wang, C., Zhou, J., Jiang, K., \& Liu, J. (2016). Differences in leaf functional traits and allelopathic effects on seed germination and growth of Lactuca sativa between red and green leaves of Rhus typhina. South African Journal of Botany, 111, 17-22. 
Wientjes, I.E., \& Croce, R. (2011). The light-harvesting complexes of higher plant Photosystem I: Lhca1/4 and Lhca2/3 form two red-emitting heterodimers. Biochemical Journal, 433, 477-485.

Yabe, T., Morimoto, K., Nishio, K., Terashima, I., \& Nakai, M. (2004). The Arabidopsis chloroplastic NifU-like protein CnfU, which can act as an iron-sulfur cluster scaffold protein, is required for biogenesis of ferredoxin and Photosystem I. Plant Cell, 16, 993-1007.

Yuan, Y.-W., Rebocho, A.B., Sagawa, J.M., Stanley, L.E., \& Bradshaw, H.D. Jr. (2016). Competition between anthocyanin and flavonol biosynthesis produces spatial pattern variation of floral pigments between Mimulus species. Proceedings of the National Academy of Sciences of the United States of America, 113, 2448-2453.

Yasuno, N., Takamure, I., Kidou, S., Tokuji, Y., Ureshi, A.N., Funabiki, A., Ashikaga, K., ........Kato K. (2009). Rice shoot branching requires an ATP-binding cassette subfamily G protein. New Phytologist, 182, 91-101.

Yu, Z., Zhang, Q., Zheng, X., Huang, X., \& Peng, C. (2019). Anthocyanin accumulation in juvenile Schima superba leaves is a growth trade-off by consuming energy for adaptation to high light during summer. Journal of Plant Ecology, 12, 507-519.

Zeliou, K., Manetas, Y., \& Petropoulou, Y. (2009). Transient winter leaf reddening in Cistus creticus characterizes weak (stress-sensitive) individuals, yet anthocyanins cannot alleviate the adverse effects on photosynthesis. Journal of Experimental Botany, 60, 3031-3042.

ang, S., Apel K., \& Kim, C. (2014). Singlet oxygen-mediated and EXECUTER-dependent signalling and acclimation of Arabidopsis thaliana exposed to light stress. Philosophical Transactions of the Royal Society B, 369, 20130227.

Zhang, Z., Ji, R., Li, H., Zhao, T., Liu, J., Lin, C., \& Liu, B. (2014). CONSTANS-LIKE 7 (COL7) is involved in phytochrome B (phyB)-mediated light-quality regulation of auxin homeostasis. Molecular Plant 7, 14291440. 
Zhang, H., Zhong, H., Wang, J., Sui, X., \& Xu, N. (2016). Adaptive changes in chlorophyll content and photosynthetic features to low light in Physocarpus amurensis Maxim and Physocarpus opulifolius “Diabolo”. Peer Journal 4: e2125.

Zhang, T.J., Chow, W.S., Liu, X.-T., Zhang, P., Liu, N., \& Peng, C.-L. (2018). A magic red coat on the surface of young leaves: anthocyanins distributed in trichome layer protect Castanopsis fissa leaves from photoinhibition. Tree Physiology, 36, 1296-1306. 


\section{Figure legends}

Figure 1. (A) In vivo differential absorbance spectra of epidermal anthocyanins. Measurements were performed on intact leaves in red and green individuals of the same genotype (Photinia $\times$ Fraseri "Red Robin" and Parthenocissus quinquefolia) or of different cultivars (red-leafed Ocimum basilicum cv. "Purple Ruffle” and cv. “Red Rubin” compared to green-leafed O. basilicum cv. “Tigullio”) using a spectrofluorimeter equipped with a double arm optical fibre bundle. Absorbance spectra were then calculated using the protocol of Agati, Cerovic, Pinelli, \& Tattini (2011), by measuring the Chl fluorescence excitation over the 350-700 nm spectral region, for emission at $730 \mathrm{~nm}$. Theoretical background: the Chl Fluorescence Excitation Ratio (ChlFER) of green to red leaves corresponds to the ratio of epidermal transmittance $(\mathrm{EPT})$ and, hence, ChlFER green/red $=$ EpT green/red. According to the Beer-Lambert's law, $\mathrm{A}=-\log \mathrm{T}$, thus $\log$ ChlFER is the difference in epidermal absorbance of red to green leaves: logChlFERgreen/red = EpAred - EpAgreen. Since fluorescence spectroscopy is a highly sensitive technique and fluorescence emitted by chlorophylls is intense, logChlFER is more accurate than reflectance spectroscopy in measuring in vivo absorbance of leaf epidermis, especially in the UV-blue waveband. In fact, reflectance is very low over the $350-480 \mathrm{~nm}$ waveband, due to high absorbance of both epidermally located phenylpropanoids and photosynthetic pigments located in the adaxial mesophyll layers. (B) Light absorption spectra of plant photoreceptors phytochromes (PR/PFR) and cryptochromes (CRY). Modified from Landi, Zivcak, Sytar, Brestic \& Allakhverdiev (2020), with permission from BBA - Bioenergetics ${ }^{\circledR}$ Elsevier 2020.

Figure 2. Heat map showing differentially expressed genes in purple ('Red Rubin’) and green ('Tigullio’) Ocimum basilicum leaves grown for four weeks in full sunlight. Data are $\log _{2}$ fold change of transcript abundance of Purple/Green basil. Leaf samples were collected at four different times of the day (08:30, 12:00, 14:30 and 17:30 h), from five replicate plants, and pooled together prior to analysis (Tattini et al., 2017). Gene expression levels 
were calculated using the reads per Kilobase per million mapped reads (RPKM) method (Mortazavi, Williams, McCue, Schaeffer, \& Wold, 2008), by mapping raw reads of green and purple basil to the basil reference transcriptome. The basil reference transcriptome was assembled using the Illumina platform. Sequence reads have been deposited at the Sequence Read Archive (SRA) of the National Center of Biotechnology Information (NCBI, Bethesda, MD, USA) under accession number SRA313233. Data have been analysed using the Z-test (Kal et al., 1999), with $\log _{2}$ fold change $> \pm 1$ and adjusted $P$-value $<0.05$, to identify genes with significantly different expressions (CLC Genomic Workbench, Qiagen, Hilden, Germany). The whole dataset of DEG of purple vs green basil leaves is shown in Table S1 in Supporting Information

Figure 3. Response curves of net photosynthesis $\left(A_{N}\right)$ to changes in light irradiance ( $A_{N}$ :PPFD curves) in fully developed leaves of reddish vs green cultivars. (A) Response curves of green (green symbols) and black (red symbols) Ophiopogon planiscapus 'Nigrescens’ grown in natural sunlight (redrawn from Hatier, Clearwater, \& Gould, 2013). (B) Response curves of Physocarpus amurensis 'Maxim’ (green symbols) and Physocarpus opulifolius ‘Diablo' (red symbols) grown under natural sunlight (1000-1500 $\mu$ mol quanta m-2 s-1 (redrawn from Zhang, Zhong, Wang, Sui, \& Xu, 2016). (C) Response curves of Acer platanoides 'Summer Shade' (green symbols) and 'Crimson King' (red symbols) grown for three month in full sunlight (PPFD at midday 1800 mmol quanta m-2 s-1, Fini, unpublished data). (D) Response curves of green (Tigullio, green symbols) and purple (Red ... bin, red symbols) Ocimum basilicum grown for four weeks in full sunlight (PPFD at midday 1850 mmol quanta m-2 s-1, redrawn from Tattini et al. 2017). Red-white (B,C) or red-blue leds (A,D) have no clear effect on the shape of A:PPFD response curves. This is likely because red photon intensity largely exceeds that of blue photons in red-blue leds source, thus making of minor significance the effect of anthocyanin-induced reduction of blue light transmittance, particularly in the low PPFD range (Loreto, Tsonev, \& Centritto, 2009; Terashima, Fujita, Inoue, Chow, \& Oguchi, 2009). 


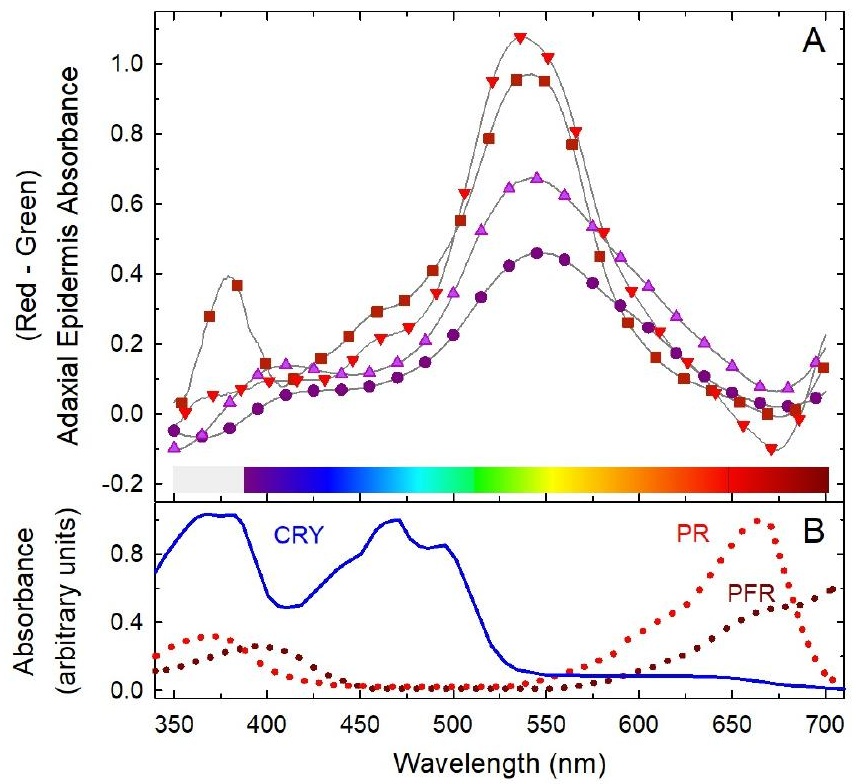


$\mathrm{J}$ domain-containing protein required for chloroplast accumulation response 1 (JAC1) Chlorophyll a-b binding protein CP24 10A (CAP10A)

Chlorophyll a-b binding protein 4 (LHCA4)

NifU-like protein 3 (NIFU3)

Protein CURVATURE THYLAKOID 1A (CURT1A)

Protein FAR-RED IMPAIRED RESPONSE 1 (FAR1)

Protochlorophyllide-dependent translocon component 52 (PTC52)

Cell division protein FtsZ homolog 1 (FtsZ1)

Photosystem II stability/assembly factor HCF136 (HCF136)

(Photosystem I reaction center subunit II-1 (PSAF)

Photosystem I reaction center subunit $\mathrm{V}$ (PSAG)

Rhotosystem I subunit O (PSI-O)

Farly light-induced protein 2 (ELIP2)

Ohlorophyllase-1 (CLH1)

NON-YELLOW COLORING 1 (NYC1)

Thioredoxin-like protein CDSP32 (CDSP32)

Plastid-lipid-associated protein 6 (PAP6)

Protein EXECUTER 1 (EX1)

Plotein PHYTOCHROME KINASE SUBSTRATE 1 (PKS1)

Protein PHYTOCHROME KINASE SUBSTRATE 3 (PKS3)

P otein PHYTOCHROME KINASE SUBSTRATE 4 (PKS4)

Protein AUXIN RESPONSE 4 (AXR4)

protein BPS1 (BPS1)

rrotein LONGIFOLIA 1 (LNG1)

Piotein LONGIFOLIA 2 ( LNG2)

Expansin-A1 (EXPA1)

IFkpansin-A4 (EXPA4)

Expansin-A8 (EXPA8)

Expansin-A10 (EXPA10)

$T$ anscription factor TCP2 (TCP2)

Transcription factor TCP4 (TCP4)

Transcription factor TCP20 (TCP20)

Beta-carotene isomerase D27-like protein (DWARF27)

$\mathrm{ABC}$ transporter $\mathrm{G}$ family member 5 ( $A B C G 5)$

$A B C$ transporter $G$ family member 11 (ABCG11)

Protein AUXIN-REGULATED GENE INVOLVED IN ORGAN SIZE (ARGOS)

L-type lectin-domain containing receptor kinase I.9 (LECRK19)

Constans $1(\mathrm{CO}-1)$

Constans $16(\mathrm{CO}-16)$

Homeobox-leucine zipper protein HAT5 (ATHB1)

Homeobox-leucine zipper protein HAT4 (ATHB2)

Homeobox-leucine zipper protein ATHB-12 (ATHB12)

Transcription factor PRE3 (BHLH135)

Transcription factor bHLH144 (BHLH144) 

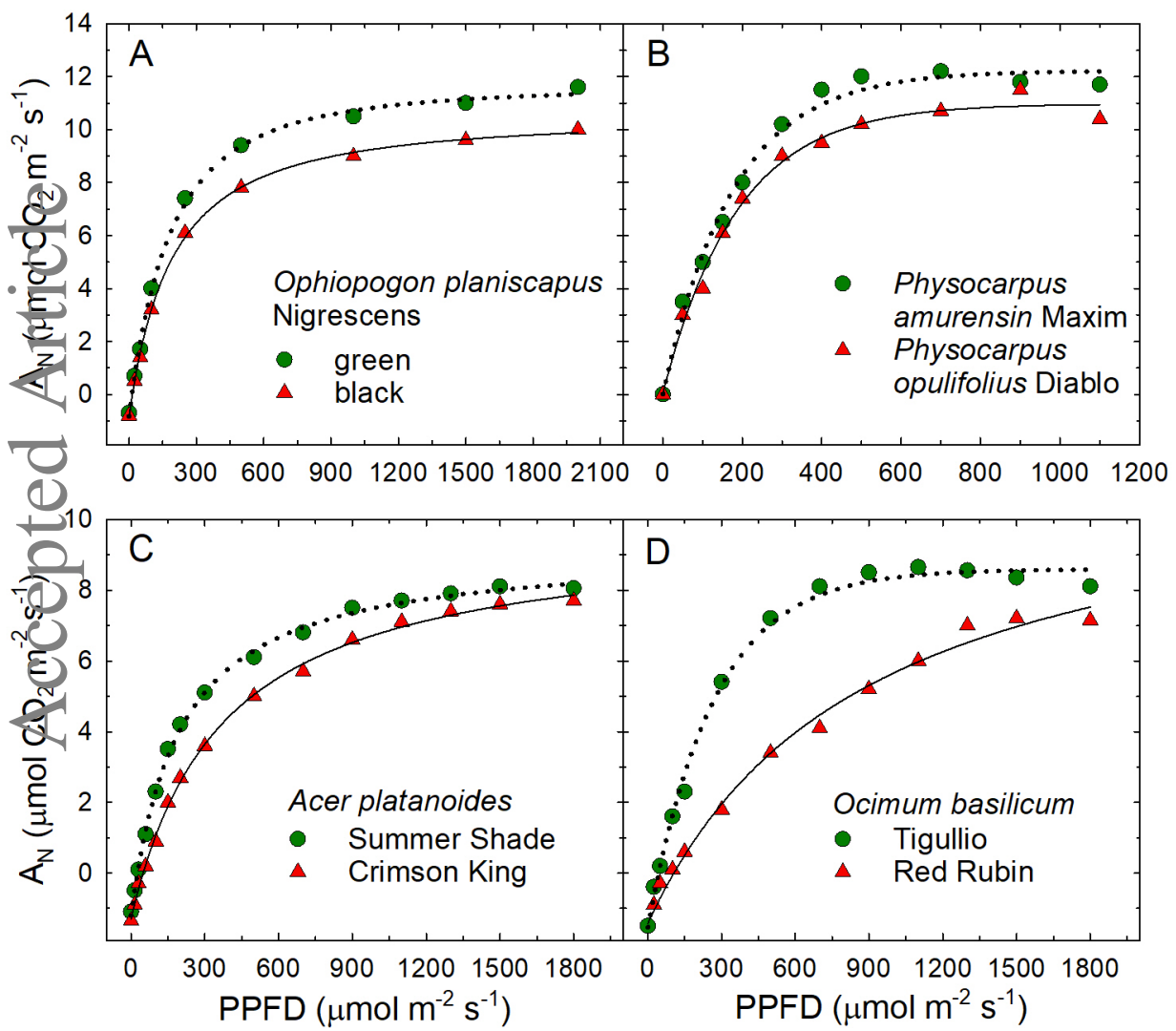
Fig. S1. UV-vis absorbance spectra of glucosides (glu) and p-coumaroyl glucosides (coum glc) of dihydroxy (cyanidin, Cyan) and trihydroxy (malvidin, Malv) B-ring-substituted anthocyanins. Spectra were recorded as reported in: Ferrandino, A., Pagliarani, C., Carlomagno, A., Novello, V., Schubert, A., \& Agati, G. (2017). Improved fluorescence-based evaluation of flavonoid in red and white winegrape cultivars. Australian Journal of Grape \& Wine Research, 23, 207-214.

Table S1. List of Differentially Expressed Genes (DEGs) between purple and green basil leaves. Data are log2 fold change of transcript abundance of Purple/Green basil. 